\title{
Rheological Behaviour and Model for Porous Rocks Under Air-Dried and Water-Saturated Conditions
}

\author{
S. Okubo*, K. Fukui and X. Gao
}

Department of Systems Innovation, The University of Tokyo, Tokyo, Japan

\begin{abstract}
Most rocks exhibit viscoelastic properties or time-dependent behavior during deformation. For example, peak strength and Young's modulus increase with loading rate in uniaxial compression tests. In the creep test, strain increases over time even though stress is maintained at a predetermined value. Such viscoelastic behavior is especially notable in porous rocks such as tuff and weathered rocks. In this study, we first present a brief review of the viscoelastic properties of porous rocks, and then propose a new rheological model based on constitutive equations previously proposed by the authors. The model consists of a spring and a dashpot. We assume that the constitutive equation described in a previous study can be applied to the spring. The viscosity of the dashpot is low prior to loading, and increases gradually with progressive loading. In creep testing at low stress levels, strain of the dashpot corresponds to creep strain because the spring constant does not decrease significantly at low stress levels. Experimental analysis of muddy sandstone, Oya tuff, Tage tuff and Kawazu tuff is compared with theoretical predictions. The measured and theoretical stress-strain curves are in good agreement. The increase in peak strength and Young's modulus with loading rate is well simulated by the model. The most important result of this study is that even at low stress conditions, strain of the dashpot is considerably larger than considered in previous studies. Our model provides a sound simulation of the difference in Young's moduli between air-dried and water-saturated conditions, where the difference is assumed to reflect the partitioning of strain into the dashpot. In water-saturated conditions, strain of the dashpot increases more rapidly than in air-dried conditions, and Young's modulus is consequently relatively small.
\end{abstract}

\section{INTRODUCTION}

It is well known that rocks possess viscoelasticity and exhibit time-dependent behavior during deformation $[1,2]$. In particular, an increase in creep strain with time is observed, even at relatively low levels of stress, in porous tuff and in rock whose porosity has increased via weathering [3]. For example, Okubo and Fukui [4] have reported that for stress levels representing $30 \%$ of peak strength, Tage tuff continues to undergo gradually increasing creep strain more than 5 years after the initiation of the test. The dependency of peak strength and Young's modulus of these rock types on loading rate is also experimental evidence of their viscosity or time-dependence. Okubo et al. [5] reported that Tage tuff and Oya tuff record $6-15 \%$ increases in uniaxial compressive strength and $5-8 \%$ increases in $E_{50}$, the tangential Young's modulus at a stress corresponding to $50 \%$ of the peak strength, for every tenfold increase in loading rate.

Increases in creep strain at relatively low stresses and variations in $\mathrm{E}_{50}$ with loading rate are indicators of the important role of the viscous characteristics of a material, even at stresses below $50 \%$ of peak strength. If we assume that the viscous characteristics are indeed important, irrecoverable strain (viscous strain) will increase with increasing stress, such that the resulting stress-strain curve tends to be concave downward. Measured results indicate, however, that the linearity of the stress-strain line is not

*Addres correspondence to this author at the Department of Systems Innovation, The University of Tokyo, Tokyo, Japan;

E-mail: ttokubo@sys.t.u-tokyo.ac.jp necessarily diminished below $50 \%$ of peak strength [4]. This point is rather difficult to explain.

Highly porous tuff and rock whose porosity has increased as a result of weathering have different strengths in air-dried (dry) conditions compared with water-saturated (wet) conditions; for example, the peak strength of wet Oya tuff is less than half that of the same rock in dry conditions [6]. This weakening has been attributed to acceleration of stress corrosion by the supply of water [7, 8]. It is difficult to explain the difference in Young's modulus between dry and wet rock. Young's modulus is generally considered to be a constant of elasticity for a material, irrespective of the presence or absence of water; however, Young's modulus is considerably lower in wet tuff than in dry equivalents. If one considers the differences in strain between the dry and wet conditions to be irrecoverable strain, one can explain the difference in Young's modulus between the contrasting conditions. However, it then becomes difficult to explain the observed results described in the above paragraph, such as the relatively good linear fit of the stress-strain line at relatively low stresses. This approach also leaves several other aspects unexplained.

The present research analyzed mainly porous rock samples to investigate the deformation characteristics of four rock types from low levels of stress up to peak strength. The analyzed rock types are muddy sandstone, Tage tuff, Oya tuff and Kawazu tuff. On the basis of experimental findings, we propose a rheological model, based on constitutive equations, that takes into account irrecoverable strain. The experimental results are then compared with the predictions of the model. 
Table 1. Porosity, Uniaxial Compressive Strength and Elastic Moduli of Sample Rocks

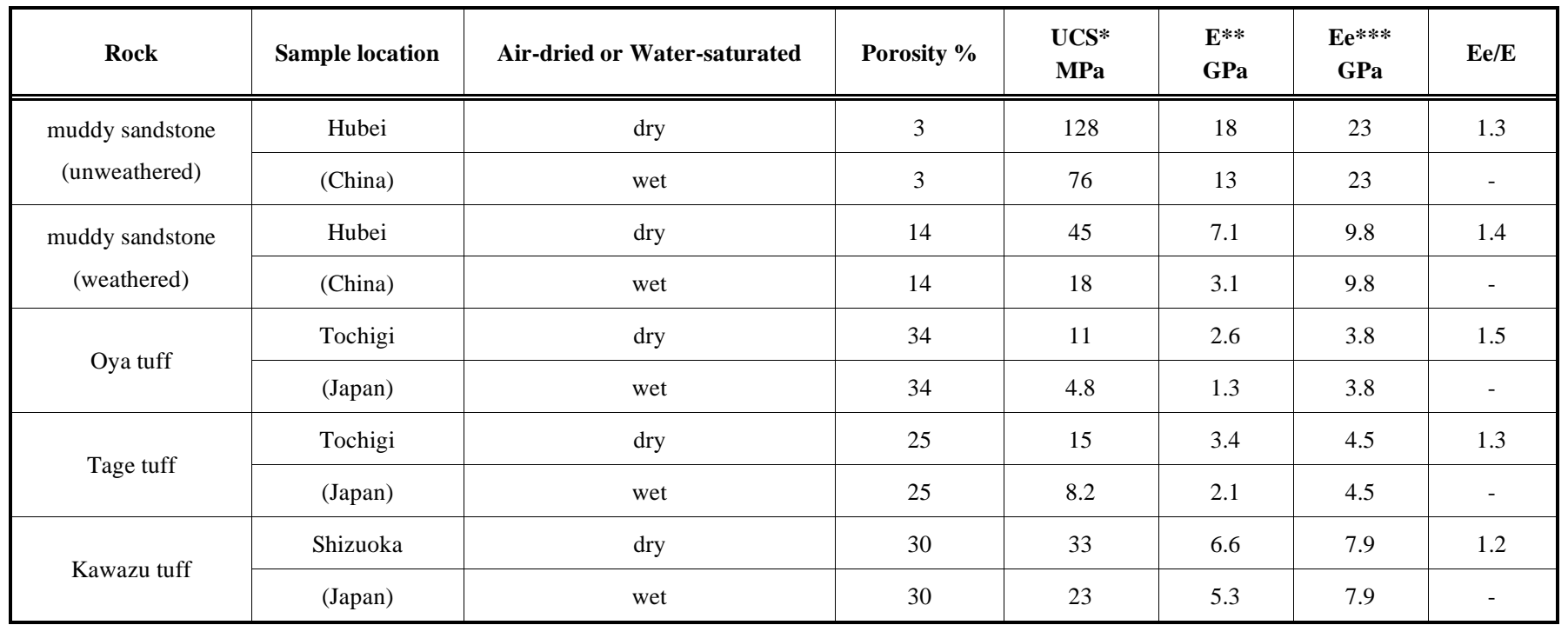

*UCS: Uniaxial compressive strength.

***: Young's modulus.

$* * *$ Ee: Modulus of unloading curve $(=1 / \lambda \mathrm{o})$.

\section{Rock Samples}

Table 1 summarizes the properties of the rock types used in the present investigation. The test samples measured 2.5 $\mathrm{cm}$ in diameter and $5 \mathrm{~cm}$ in height. The uniaxial strain rate was $10^{-5} \mathrm{~s}^{-1}$. The test results described below were all taken at this strain rate, unless stated otherwise. The descriptions of how the samples were prepared and stored can be found in previous papers $[9,10]$. " $E \mathrm{e}$ " in Table $\mathbf{1}$ is the slope of the unloading curve: the tangent of the curve obtained while unloading the sample from $30 \%$ to $20 \%$ of peak strength.

Samples of muddy sandstone were obtained in the upper weathered portion (weathered sandstone) and lower unweathered portion of a landslide area within Hubei Province, China [11]. The exposed layer consisted mainly of quartz particles about $0.2 \mathrm{~mm}$ in size. Many empty pores were found around the particles. The lower layer of the muddy sandstone also consisted dominantly of quartz, but calcite was also present. Minor clay minerals, sericite and carbonaceous material was observed surrounding the quartz grains, but the concentration of clay minerals was relatively low in both samples. The porosity of the unweathered layer was $3.0 \%$, and $14.3 \%$ in the upper layer. It is certain that this higher porosity lowered the peak strength of the muddy sandstone.

The Oya tuff is a green tuff extracted in Oya Town, Utsunomiya City, Tochigi Prefecture, Japan [12]. The tuff is composed of plagioclase and quartz. The Tage tuff used for this testing was taken from the lower layers of the Oya tuff, and contains higher concentrations of calcite and is harder than ordinary Oya tuff. The sampled tuff presented a more bluish color than ordinary Oya tuff, due to the presence of blue minerals that had formed from glassy material in the original tuff. Some flow layers, with the appearance of welded structures, were observed. Kawazu tuff is a light gray stratified tuff extracted in Kawazu Town, Shizuoka Prefecture, Japan. Flow layers were also found which appeared to be welded structures.
It is well known that uniaxial compressive strength (UCS) diminishes with increasing porosity $n_{\mathrm{e}}$ [13-15] as summarized in Table $\mathbf{1}$.

Let us examine the difference in Young's modulus between dry and wet rock, which has not been clearly explained by previous research. Fig. (1) graphically presents the values of strength and Young's modulus for dry and wet rock already given in Table $\mathbf{1}$. There are insufficient data here, but the correlations between the values in the two conditions are quite good for both strength and Young's modulus. As is clear from the figure, the strength in the wet rock had fallen to $58 \%$ of that in the dry rock. This shows the reduction in strength mentioned in the previous section, probably due to the acceleration of stress corrosion induced by the plentiful supply of water $[16,17]$. Young's modulus also fell in the wet rock to $67 \%$ of the value in dry rock. As is well known, strength is sensitive to structure and can be greatly influenced by small changes in other parameters. It is

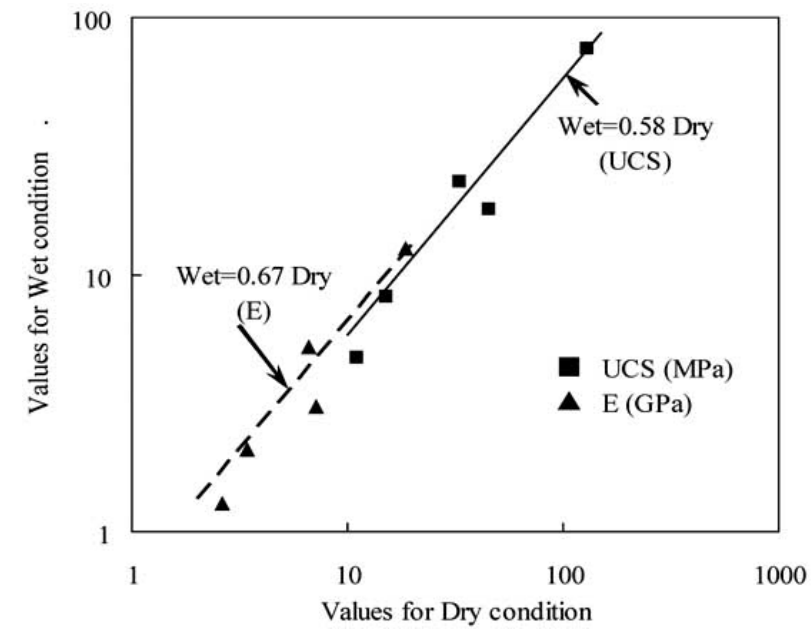

Fig. (1). Uniaxial compressive strength and Young's modulus in air-dried and water-saturated conditions. 
not easy to understand the reason for the large changes in Young's modulus. The measured Young's modulus would be the average modulus throughout the sample volume, and is insensitive to the shape or structure of the sample. It is probably also significant that the magnitude of change in Young's modulus is similar to the change in strength.

We deduce from the above observations that irrecoverable strain plays a large role before peak strength is reached; it is possible that the reason for the drop in apparent Young's modulus in wet rock is the large increase in irrecoverable strain, rather than a change in elastic deformation. We have developed a rheological model on the basis of the above reasoning. In developing the model, special attention has been paid to the experimentally observed linearity of the stress-strain curve at low stresses. There are numerous rheological models that consider viscosity and time-dependence, but the linearity of the stressstrain curve severely limits the applicability of existing models.

\section{Rheological Model Considering Irrecoverable Strain}

Okubo et al. [5] proposed the combination of a spring and dashpot in series (Fig. 2) as a candidate rheological model that expresses the characteristics of rock types with prominent loading-rate dependence of Young's modulus. The spring element represents recoverable strain at given time and the spring constant is able to change with time. The dashpot element represents irrecoverable strain and the viscous rate is also allowed to change with time. A slider is often used as an element in rheological models to represent plasticity, but was left out of this model for the sake of simplicity.

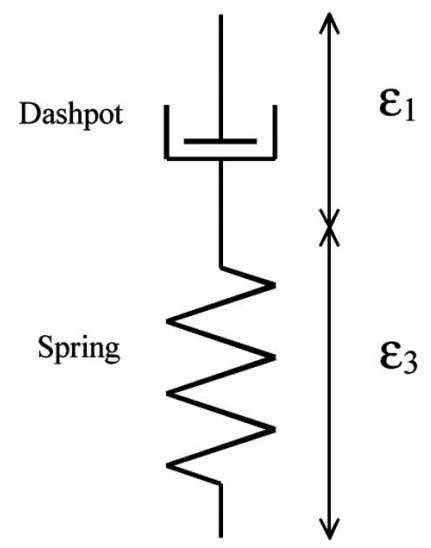

Fig. (2). A physical or rheology model with a spring and a dashpot.

Let us borrow from Okubo et al. [5] the symbols $\varepsilon$ for total strain, $\varepsilon_{1}$ for the irreversible strain of the dashpot, and $\varepsilon_{3}$ for the elastic strain of the spring. The subscripts 1 and 3 are deliberately chosen here as they are closely related to primary and tertiary creep. Creep stages often involve secondary creep as well, but secondary creep is neglected here for the sake of simplicity.

$\varepsilon=\varepsilon_{1}+\varepsilon_{3}$

The following expression [18, 19], found by trial and error, was used to estimate irreversible strain: $\frac{d \varepsilon_{1}}{d t}=a_{1} \frac{\sigma^{n_{1}}}{\varepsilon_{1}^{m_{1}}}$

Here, $a_{1}$ is the dominant parameter determining the magnitude of $\varepsilon_{1}$ and $n_{1}$ is a constant that expresses stressdependence. The results of previous creep tests indicate that the creep strain rate decreases with increasing creep strain during initial deformation [4, 19]. The constant $m_{1}$ was chosen to illustrate this tendency to resist deformation with increasing strain.

We employed a set of constitutive equations previously reported that allow variable compliance $[20,21]$ to express the spring constant in the rheological model (Fig. 2). In these equations, $\lambda$ is the compliance and $\varepsilon_{3}$ is written as follows:

$\varepsilon_{3}=\lambda \sigma$

$\frac{d \lambda}{d t}=a_{3} \sigma^{n_{3}} \lambda^{m_{3}}$

$\varepsilon_{1}$ is the dominant parameter up to about $80 \%$ of peak strength, although this also depends on the values of the constants in the constitutive equations. $\varepsilon_{3}$ dominates above $80 \%$ of peak strength. Accordingly, the constitutive equations proposed in this study express almost the same rock characteristics at peak strength and in the post-failure region with the previous constitutive equations described by Okubo and Fukui [21]. For example, the peak strength found in the fixed strain rate test increases in proportion to the $1 /\left(n_{3}+1\right)$ power of the strain rate.

We now solve the constitutive equations shown in Eqs. (1-4) (the rheological model in Fig. (2) under some simple loading conditions. The investigated region will be the prefailure region, so changes in $\lambda$ remain small.

A. Constant stress rate $d \sigma / d t=C$

Recently, strength tests are commonly carried out at constant strain rate. Nevertheless, constant strain rates require series solutions, so for analytical convenience, let us examine constant stress rate tests. At initial time $t=0$, let us assume $\varepsilon_{1}=0$ and $\sigma=0$; this leads to the following equation:

$\varepsilon_{1}=\left(\frac{a_{1}}{C} \frac{m_{1}+1}{n_{1}+1}\right)^{1 /\left(m_{1}+1\right)} \sigma^{\left(n_{1}+1\right) /\left(m_{1}+1\right)}$

The strain of the entire body takes the form

$\varepsilon=\left(\frac{a_{1}}{C} \frac{m_{1}+1}{n_{1}+1}\right)^{1 /\left(m_{1}+1\right)} \sigma^{\left(n_{1}+1\right) /\left(m_{1}+1\right)}+\lambda \sigma$

If the argument here is confined to comparatively low stress levels, we may assume that $\lambda$ maintains its initial value $\lambda_{0}$. As we see from Eq. (6), if $\left(n_{1}+1\right) /\left(m_{1}+1\right)=1, \varepsilon$ and $\sigma$ are proportional to each other and the stress-strain curve becomes a straight line. Therefore, as long as the following condition is satisfied, the stress-strain curve can be described as relatively close to linear, in spite of viscoelastic or timedependent characteristics shown by the rock.

$0.7 \leq\left(n_{1}+1\right) /\left(m_{1}+1\right) \leq 1.3$ 
There is some arbitrariness in the range of $\left(n_{1}+1\right) /\left(m_{1}+1\right)$ (see Appendix A).

\section{B. Creep $\sigma=$ Constant}

The solution is the simplest when the stress is set to be constant. If we select $\varepsilon_{1}=0$ at $t=0$, we can obtain Eq. (8) from Eq. (2). The solutions for the change of $\varepsilon_{3}$ in Eqs. (3) and (4) have already been obtained [20,21]. The change of $\varepsilon_{3}$ is small at low stress levels, so usually ignored.

$\varepsilon_{1}=\left\{a_{1}\left(m_{1}+1\right)\right\}^{] /\left(m_{1}+1\right)} \sigma^{n_{1} /\left(m_{1}+1\right)} t^{1 /\left(m_{1}+1\right)}$

Thus, we know that creep strain will increase with the $1 /\left(m_{1}+1\right)$ power of time. Fig. (3) shows an example of experimentally determined creep strain; at low stress levels, the creep strain generally increases in proportion to $t^{0.1}$ [4]. If $1 /\left(m_{1}+1\right)=0.1$, then we can solve to find

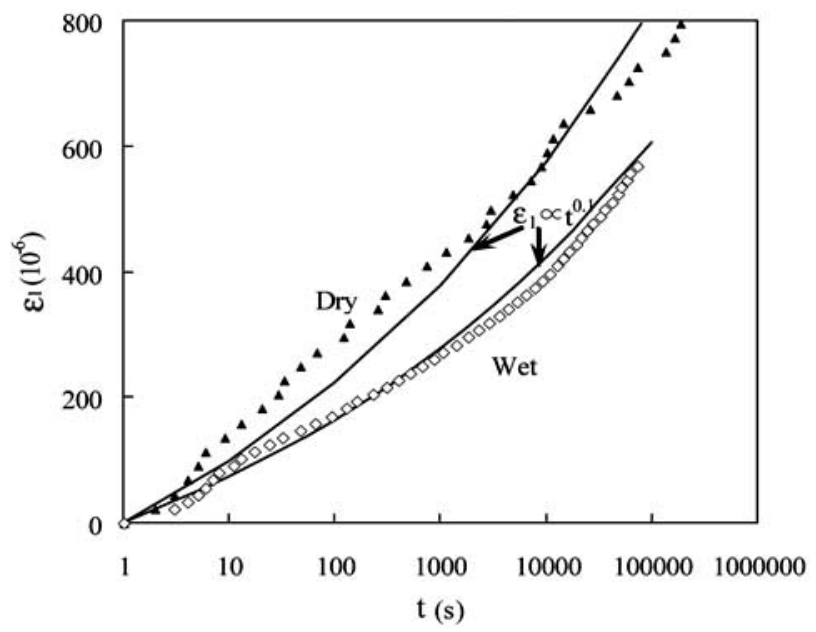

Fig. (3). Increase of creep strain with time. Sample rock is Kawazu tuff. Creep stress levels are $85 \%$ and $90 \%$ for air-dried and water saturated conditions, respectively.

$m_{1}=9$

Creep strain is also predicted to increase after a fixed time by the $n_{1} /\left(m_{1}+1\right)$ power of stress, and most are seen to fit within the following range [22]:

$1<n_{1} /\left(m_{1}+1\right)<3$

\section{Relaxation $\varepsilon=C$}

Relaxation requires a series solution. Below, the initial stress during relaxation is low, so we can pursue this investigation under the assumption that changes in $\lambda$ can be neglected.

We obtain the following from Eqs. (1) and (3):

$\sigma=\left(\varepsilon-\varepsilon_{1}\right) / \lambda$

We represent the increase in irrecoverable strain after a fixed time by $\Delta \varepsilon_{1}$ and the relaxation (change in stress) by $\Delta \sigma$. When changes in $\lambda$ are neglected, the following equality emerges:

$\Delta \sigma=-\Delta \varepsilon_{1} / \lambda$
For a short time from the beginning of the relaxation test, $\Delta \sigma$ is small, so $\Delta \varepsilon_{1}$ can be calculated from Eq. (2) assuming that the stress change is negligibly small. As can be deduced from the above creep strain equation (8), $\lambda$ is not included in the $\Delta \varepsilon_{1}$ calculated this way, so during the initial phase of relaxation, $\Delta \varepsilon_{1}$ can be considered to be unaffected by $\lambda$.

D. Generalized relaxation

The fundamental equation for generalized relaxation proposed by Fukui et al. [23] can be rewritten as

$\varepsilon+\alpha \sigma=C$

This represents relaxation when $\alpha=0$; the larger the value of $\alpha$, the more closely this resembles creep. If Eq. (3) is substituted into Eq. (13), Eq. (13) can be re-arranged into

$\varepsilon_{1}+(\lambda+\alpha) \sigma=C$

Thus, in generalized relaxation, the compliance of the spring in Fig. (2) can be replaced with $(\lambda+\alpha)$. Accordingly, if we again assume that changes in $\lambda$ can be neglected because of low stress at the beginning of relaxation, we obtain

$\Delta \sigma=-\Delta \varepsilon_{1} /(\lambda+\alpha)$
$\Delta \varepsilon=\Delta \varepsilon_{1} \lambda /(\lambda+\alpha)$

As seen in relaxation, at low $\Delta \varepsilon_{1}$ the increase in $\varepsilon_{1}$ after a fixed time does not depend on $(\lambda+\alpha)$. Therefore, the strain at a fixed time would place $\Delta \varepsilon_{1}$ directly to the right of the starting point on the stress-strain curve. This is well described in the experimental results in Fig. (4) of Fukui et al. [23].

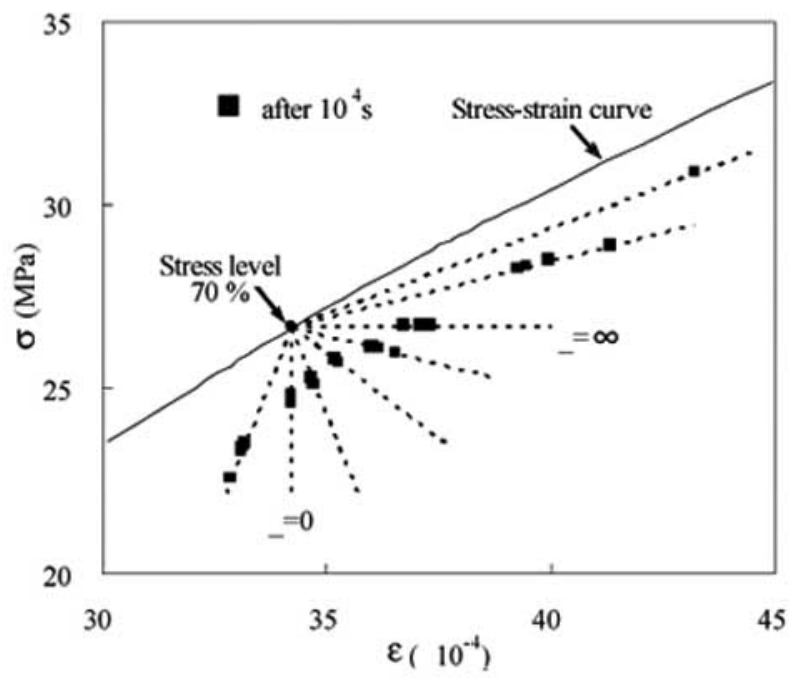

Fig. (4). Stress-strain curves in generalized relaxation [23]. Kawazu tuff in air-dried condition.

\section{E. Loading rate dependence of Young's modulus}

The stress corresponding to $50 \%$ of the peak strength at loading rate $C$ is designated $\sigma_{50}$. At this stress, the strain is given by the following expression:

$\varepsilon_{s}=\varepsilon_{1 s}+\lambda \sigma_{50}$ 
The strain at the same $\sigma_{50}$ at a loading rate of $10 \times C$ then becomes

$\varepsilon_{f}=\varepsilon_{1 s} / C^{1 /\left(m_{1}+1\right)}+\lambda \sigma_{50}$

If $\lambda$ is approximated as equal in the two preceding equations, the relative increase in Young's modulus at the tenfold loading rate is given by

$\Delta E / E=\left(\varepsilon_{s}-\varepsilon_{f}\right) \varepsilon_{s}=1-\varepsilon_{f} / \varepsilon_{s}$

$=1-\left\{\frac{\varepsilon_{1 s}}{10^{1 /\left(m_{1}+1\right)}}+\lambda \sigma_{50}\right\} /\left(\varepsilon_{1 s}+\lambda \sigma_{50}\right)$

$=\left\{1-\frac{1}{10^{1 /\left(m_{1}+1\right)}}\right\} \varepsilon_{1 s} /\left(\varepsilon_{1 s}+\lambda \sigma_{50}\right)$

We will compare these predictions with experimental results in the following section.

\section{Calculated and Measured Stress-Strain Curves}

We first address the method for determining the constants in the constitutive equations. First, $m_{1}$ was found to be 9, using Eq. (9), which was written using experimental results. There is currently no clear basis for determining the value of $n_{1}$. Two clues as to a solution to this problem are Eq. (7), based on strength tests, and Eq. (10), based on creep tests. Of the two, Eq. (10) indicates the wider range, $10<n_{1}$ $<30$, while according to Eq. (7), $n_{1}$ and $m_{1}$ must have similar values. We arbitrarily assigned $n_{1}$ a value of $12,1 / 3$ greater than $m_{1}$, and used this in the numerical simulation. The simulation indicated that the larger the value of $a_{1}$, the greater the irrecoverable strain and the lower the Young's modulus. Therefore, $a_{1}$ was selected so that the tangential Young's modulus $E_{50}$ was the same as the experimental result.

The initial value selected for compliance, $\lambda_{0}$, is the reciprocal of $E \mathrm{e}$ in Table $\mathbf{1}$ in both dry and wet conditions. Except for muddy sandstone, $n_{3}$ was based on past experimental results [5, 19]; it was estimated from the rate of increase in peak strengths at four strain rates $\left(10^{-5}, 10^{-4}, 10^{-}\right.$ $\left.{ }^{3}, 10^{-2} \mathrm{~s}^{-1}\right)$. The uniaxial compression test in muddy sandstone was performed with a stepped change in strain rate and $n_{3}$ was found from the increase or decrease in stress caused by the change in strain rate [24]. $m_{3}$ was found using the slope of the stress-strain curve after the peak strength [20]. $a_{3}$ was selected to match the experimental results for peak strength. The values used in the calculations are shown in Table 2.

Fig. (5a) shows the stress-strain curves for dry unweathered sandstone. The curves for the experimental results (thin line), calculations (thick line) and elastic strain (broken line) are all shown. The straight line representing elastic strain has the same slope as that of the initial values $(E \mathrm{e}$ in Table 1). As this figure clearly shows, the experimental results were concave upward over the low values of strain, but this was mainly due to the influence of strain at the end surfaces of the test samples; an additional factor was probably the influence from the process of closure of flat cracks. Once the stress exceeded $20 \mathrm{MPa}$, the observed stress-strain curve became nearly linear, and remained so until a stress of $100 \mathrm{MPa}$. Above that level, there was a slight trend for the curve to become concave downward until peak strength was achieved. The stress fell abruptly after peak strength, but at about $17 \mathrm{MPa}$, the reduction assumed a gentler slope.

Deformation of the end surfaces of samples was not considered in the calculations; the origin of the calculated results was shifted along the horizontal axis until a strain of about $140 \times 10^{-6}$. The calculations approximate the experimental results relatively well until peak strength. The elastic strain is shown in Fig. (5a), but it is clear that the irrecoverable strain, which is found by subtracting the elastic strain from the total strain (dashpot strain in Fig. (2) increased roughly in proportion to stress. In the vicinity of peak strength, the calculated stress-strain curve tends to be smoother and rounded before falling abruptly until zero stress is achieved. The calculated predictions are in good

Table 2. Constants in Equations (3)-(6) for Four Sample Rocks

\begin{tabular}{|c|c|c|c|c|c|c|c|}
\hline Rock & Air-dried or Water-saturated & $\begin{array}{c}\mathrm{a}_{1} \\
\mathrm{MPa}^{-\mathrm{n1}}\end{array}$ & $\begin{array}{r}\mathbf{n}_{1} \\
\mathrm{ND}\end{array}$ & $\begin{array}{r}\mathbf{m}_{1} \\
\text { ND }\end{array}$ & $\frac{\mathbf{a}_{3}}{\mathbf{M P a}^{(\mathbf{m} 3-\mathrm{n} 3)}}$ & $\begin{array}{c}\mathbf{n}_{3} \\
\mathbf{N D}^{*}\end{array}$ & $\begin{array}{c}\mathbf{m}_{3} \\
\mathrm{ND}^{*}\end{array}$ \\
\hline \multirow{2}{*}{$\begin{array}{l}\text { muddy sandstone } \\
\text { (unweathered) }\end{array}$} & dry & $8.96 \times 10^{-54}$ & 12 & 9 & $1.22 \times 10^{78}$ & 36 & 36 \\
\hline & wet & $1.06 \times 10^{-48}$ & 12 & 9 & $4.38 \times 10^{71}$ & 30 & 30 \\
\hline $\begin{array}{l}\text { muddy sandstone } \\
\text { (weathered) }\end{array}$ & dry & $1.80 \times 10^{-47}$ & 12 & 9 & $4.14 \times 10^{81}$ & 36 & 36 \\
\hline \multirow{2}{*}{ Oya tuff } & dry & $1.02 \times 10^{-41}$ & 12 & 9 & $3.29 \times 10^{23}$ & 35 & 18 \\
\hline & wet & $7.90 \times 10^{-35}$ & 12 & 9 & $1.44 \times 10^{15}$ & 16 & 8 \\
\hline \multirow{2}{*}{ Tage tuff } & dry & $7.20 \times 10^{-44}$ & 12 & 9 & $6.56 \times 10^{8}$ & 41 & 16 \\
\hline & wet & $4.29 \times 10^{-39}$ & 12 & 9 & $6.14 \times 10^{9}$ & 23 & 9 \\
\hline
\end{tabular}

*ND: non-dimensional. 
agreement with the experimental results, if one neglects the slight residual strength.

Fig. (5b) shows the stress-strain curve of the wet unweathered muddy sandstone. These experimental results tend to be qualitatively similar to those for the dry rock, but three differences are clear: the large reductions in strength and Young's modulus, and the extremely low residual strength. In addition, the stress-strain curve dropped temporarily in the vicinity of the peak strength before increasing and then decreasing abruptly once more. Rheological behavior near peak strength differs slightly from one sample to the next. A straight line was drawn in Fig. (5b) to show the elastic strain; the slope of the line is the same as that of the dry sandstone in Fig. (5a). A large proportion of strain is accounted for by irrecoverable strain, which is obtained by subtracting elastic from total strain. A key argument of this report can be seen by comparing Fig. (5a) and (5b): the elastic strain itself does not differ in the dry and wet states, although the wet-condition Young's modulus appears to diminish because the irrecoverable strain increases.
(a). Air dried.
(b). Water saturated.

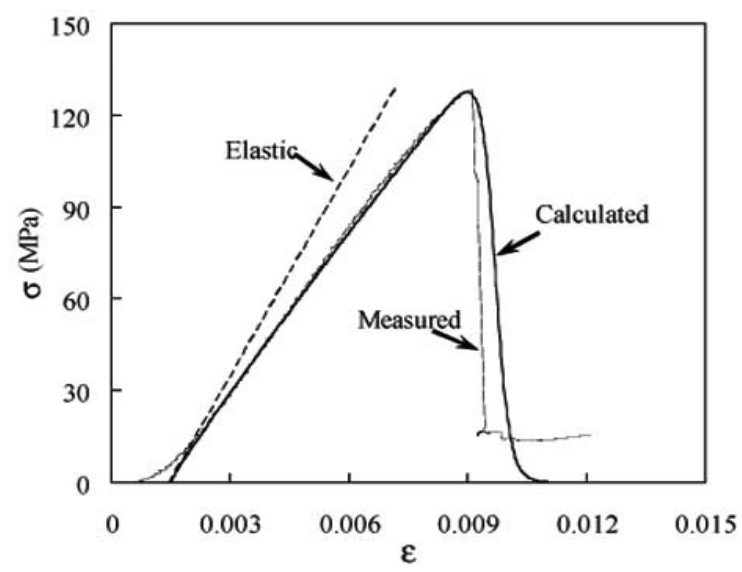

(a). Air dried.

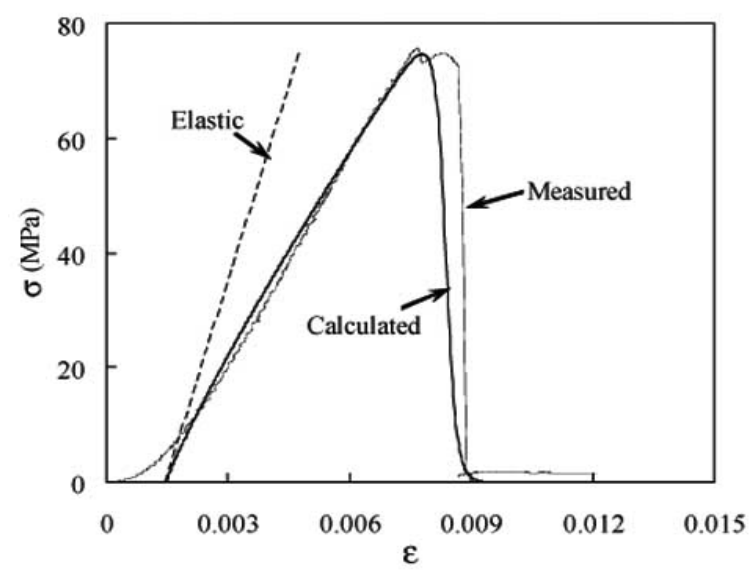

(b). Water saturated.

Fig. (5). Stress-strain curves of muddy sandstone (unweathered). A straight line denotes elastic strain.
Fig. (6a) presents the stress-strain curve for dry weathered muddy sandstone. This clearly shows lower strength and Young's modulus than the sandstone in Fig. (5a), as weathering has increased porosity. There were no great qualitative differences between the two data sets of Figs. (5a, 6a), but the stress-strain curve in Fig. (6a) was more rounded than that in Fig. (5a) in the vicinity of peak strength, and the slope of the post-peak stress curve was less steep. The calculated results are given in the same figure; they are about as similar to the measured values as those in Fig. (5a). A straight line showing the elastic strain is also drawn, but the slope of this is about 1/3 that of the straight line in Fig. (5a). This difference probably results from the higher porosity in this sample. The fraction due to irrecoverable strain $\left(=\varepsilon_{1} / \varepsilon\right)$ is somewhat larger than that in Fig. (5a).

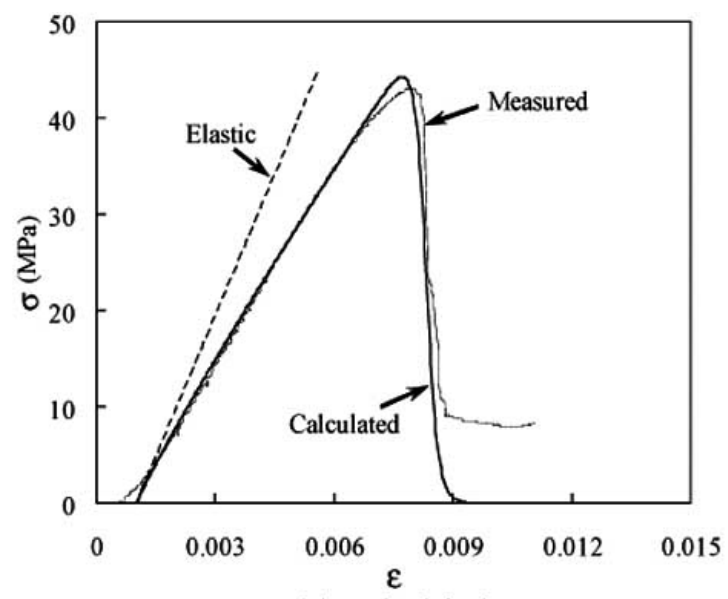

(a). Air dried.

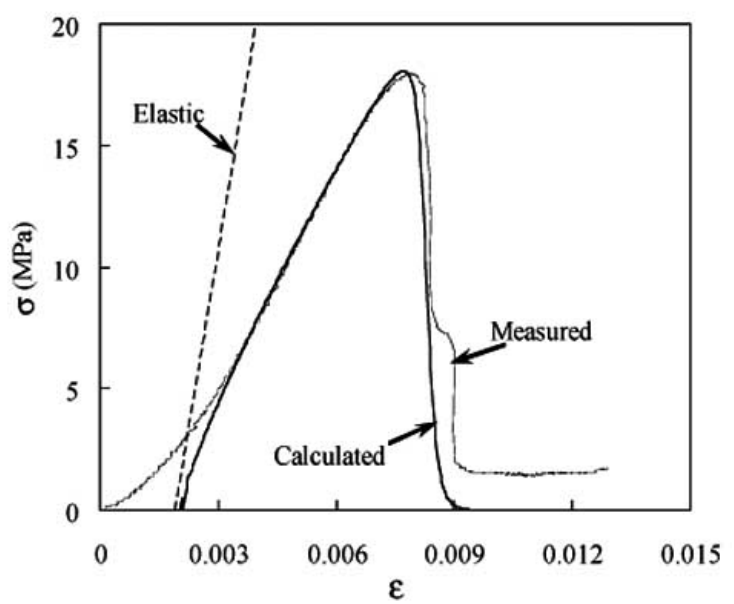

(b). Water saturated.

Fig. (6). Stress-strain curves of muddy sandstone (weathered). A straight line denotes elastic strain.

Fig. (6b) shows the stress-strain curve for wet weathered muddy sandstone. The peak strength and Young's modulus are clearly much lower than for the dry rock depicted in Fig. (6a). The experimental results show a prominent initial concave-upward trend. It is possible that this trend reflects the 
(a). Air dried.

(b). Water saturated.

influence of strain at the end surface of the test sample and the closing of cracks in the test sample. The stress-strain curve shows good linearity from $7 \mathrm{MPa}$ to $15 \mathrm{MPa}$, a range that has conventionally been considered as a linear elastic range. However, if we compare this with the straight line representing elastic strain, we see that irrecoverable strain plays an important role in this region. The slope of the line representing elastic strain was set to the same value as that for the dry weathered muddy sandstone in Fig. (6a). It seems reasonable to conclude that the experimental results fit the theoretical results to the same degree as in the other cases. In the example shown here, after peak strength, the stress fell immediately to $8 \mathrm{MPa}$ before slowing abruptly, and the rock sample supported the test load for some time before it eventually dropped sharply.

Fig. (7) shows the measured and predicted stress-strain curves for Oya tuff and the elastic strain component (dashed line). The dry specimens show a slight upward concavity in the initial portion of the curve, as noted in the muddy sandstone, but this appears only within a very narrow region. The stress-strain curve was then quite straight until $\sigma=9$ $\mathrm{MPa}$. Above this, the curve has a progressively gentler slope. The curve is rounded at the peak strength, and thereafter the stress gradually lessens. The trend of the calculation results are in good agreement with the trend of the experimental findings up to $10 \mathrm{MPa}$, but the accuracy was not at an acceptable level near the peak strength. To correct this, another term must be added to the constitutive equation; this term was not addressed in the present study. Fig. (7) also shows the measured and predicted results for wet rock; the strength and Young's modulus were substantially degraded. The difference between measured and predicted results was just acceptable. Of interest here is the stress-strain curve up to the peak strength. The elastic strain was assumed to be the same in dry and wet rock, but the two showed dramatically different strains. The constitutive equations and the rheological model treat this as a difference in the irrecoverable strains occurring in the two conditions. The data in Fig. (7) confirm the possibility of this explanation.

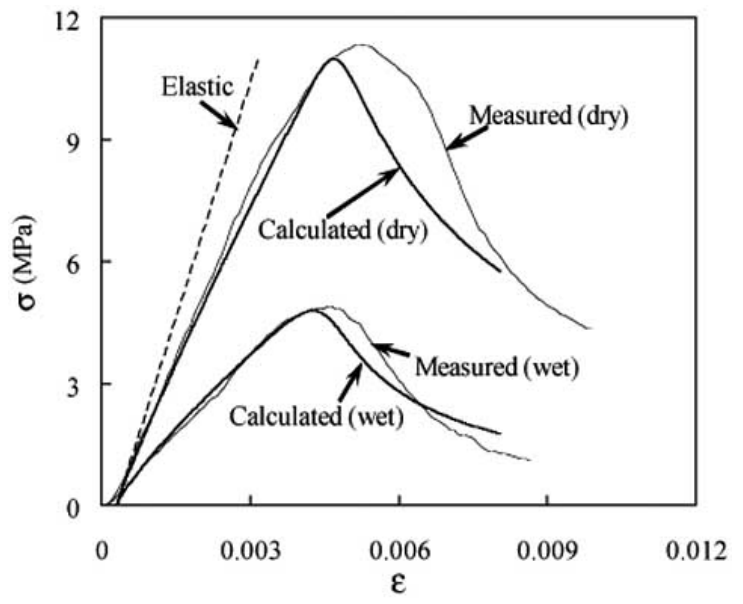

Fig. (7). Stress-strain curves of Oya tuff. A straight line denotes elastic strain.
Fig. (8) presents the results of the Tage tuff. The sample was taken from layers beneath the Oya tuff examined in this study. The Tage tuff has a higher strength and Young's modulus than the Oya tuff. The differences between dry and wet conditions were smaller than in the Oya tuff. A certain level of irrecoverable strain can be deduced from the calculated results; this was also smaller than in the Oya tuff. It was again assumed that the elastic strain was identical in the dry and wet rock to estimate the irrecoverable strain. The calculations appear to partially reproduce the experimental results.

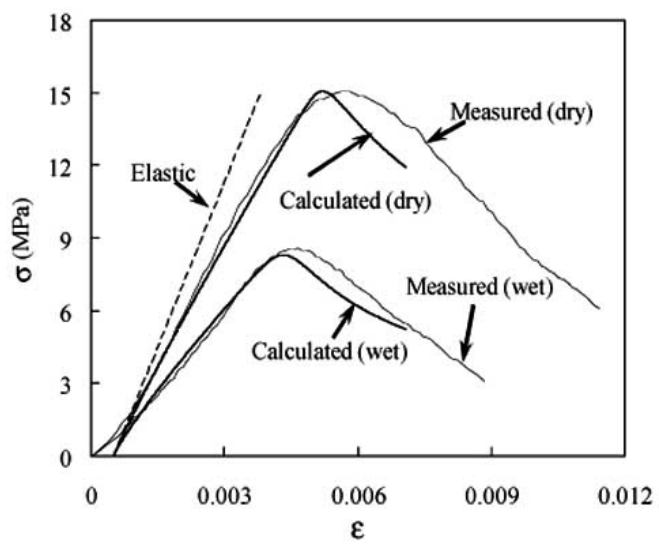

Fig. (8). Stress-strain curves of Tage tuff. A straight line denotes elastic strain.

Fig. (9) provides the results of the Kawazu tuff. The notable result here was the positive slope of the stress-strain curve in the interval after peak strength. In this sense, Kawazu tuff has the characteristics of Class II rock. Okubo and Nishimatsu [9, 25] developed a method of uniaxial compression testing using a linear combination of stress and strain as the control variable. This test was conducted on the Kawazu tuff. The measured and predicted results, in both wet and dry rock, were similar up to about $70 \%$ of peak strength, but after that, in the vicinity of peak strength, the predicted curve was more rounded and had a gentler slope. As mentioned above with regard to Oya tuff, the predictions of the constitutive equations can be improved by the addition of a term that is closely related to secondary creep, but this is beyond the scope of the current report.

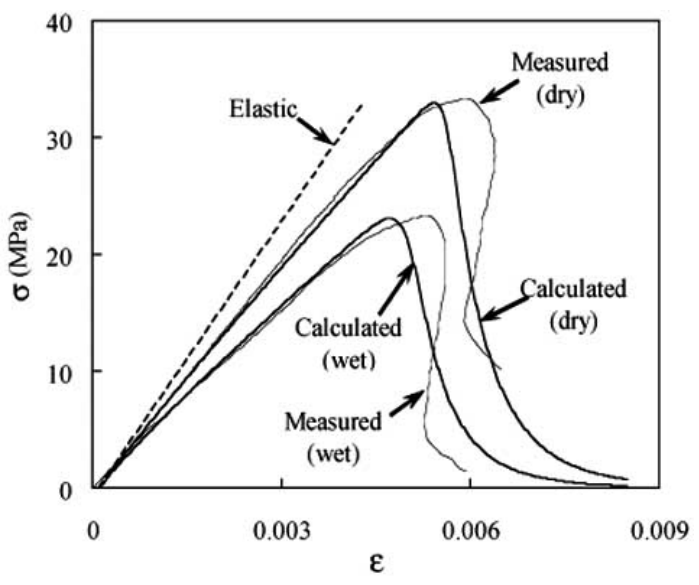

Fig. (9). Stress-strain curves of Kawazu tuff. A straight line denotes elastic strain. 
Table 3. Creep Strain in $10^{4} \mathrm{~s}$ and Loading Rate Dependence of Young's Modulus

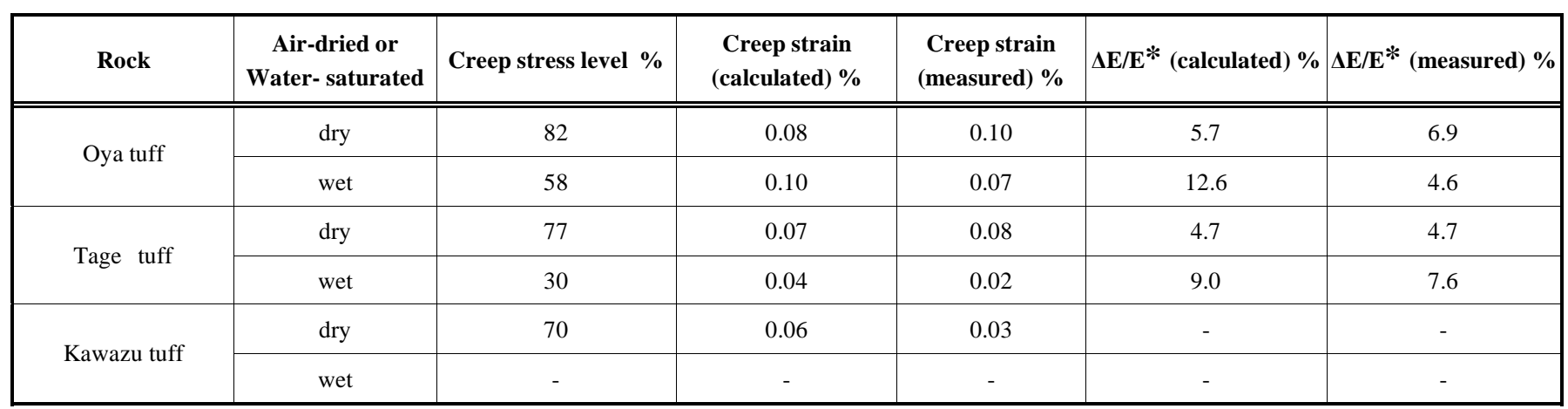

* $\Delta \mathrm{E}$ : Increase of Young's modulus $\mathrm{E}$ with ten-fold increase of loading rate.

\section{DISCUSSION}

Okubo et al. [26] subjected 9 rock types to static and punch penetration tests. In the latter test, a tungsten carbide probe with a spherical tip is forced into the rock surface at 4 $\mathrm{m} / \mathrm{s}$. The results for 8 of the rock types, with limestone excepted, showed a slope of the penetration resistance curve $K_{\mathrm{d}}$ (= penetration resistance/penetration distance) that was about 1.2 times the value of $K_{\mathrm{s}}$, the curve slope in the static results. The $E$ e/ $E$ values are provided on the right side of Table 1, and show values of $1.2-1.3$ in unweathered muddy sandstone, Kawazu tuff and Tage tuff, and 1.4 and 1.5 in the other two rock types. Elastic deformation is the chief deformation mode when penetration rate is very high; if one considers that viscoelastic phenomena account for much of the deformation in the static test, it seems reasonable that $K_{\mathrm{d}} / K$ s has some resemblance to $E \mathrm{e} / E$.

Table 3 provides a comparison of our data with previous 10,000 -s creep strain tests $[12,23,27]$. The experimental results are in good agreement with the calculation results for wet and dry Oya tuff [12] and for dry Tage tuff [12]. For wet Tage tuff [27] and dry Kawazu tuff [23], however, the calculated strains are approximately double the measured strains.

The creep test requires meticulous preparation; small variations in stress or water content of the sample cause large variations in the resulting strains. Even considering this, a discrepancy of $100 \%$ is too large to ignore. Future research should address this issue, but we suspect that $n_{1}$, the constant in the constitutive equations with the least plausible value, is most likely to be the cause of the discrepancy. Nevertheless, from a broad point of view, the differences between the experimental and calculated results are not too large.

Okubo et al. [5] analyzed 7 types of rock in terms of investigating loading rate-dependent changes in Young's modulus. They found such a dependence in Sanjome andesite, Kimachi sandstone, Tage tuff and Oya tuff, but no clear dependence in Akiyoshi marble, Inada granite or Shirahama sandstone. This kind of experiment requires high precision. Theoretical studies have not proceeded beyond qualitative arguments. Below, the measured results of the study by Okubo et al. [5] are compared with the predictions of the calculations carried out in this report.

Figs. (10,11) show the loading rate-dependence of Young's modulus for the uniaxial compression test [5]. $E_{50}$, the tangential Young's modulus at 50\% of peak strength, clearly increases with strain rate in the Tage tuff (Fig. 10). Observed increases in $E_{50}$ with a tenfold increase in strain rate are similar in wet and dry samples. $E_{50}$ in dry Oya tuff also increases with strain rate, while $E_{50}$ in wet Oya tuff increases only a little.

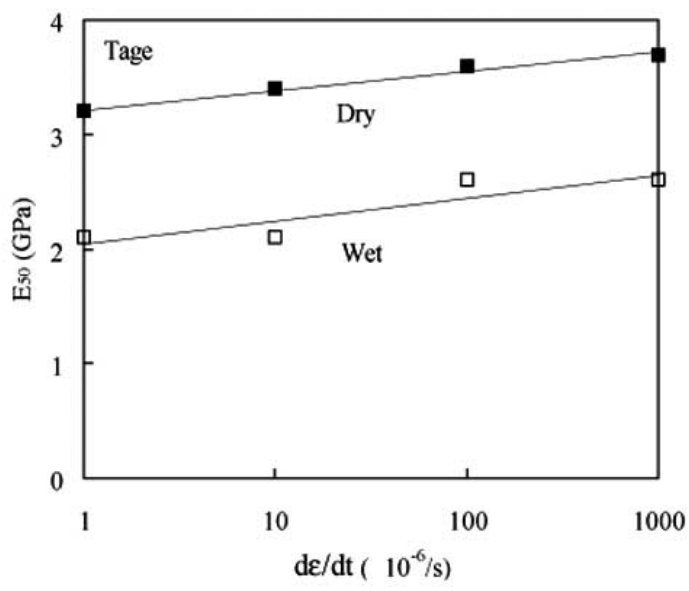

Fig. (10). Increase of Young's modulus with loading rate [5]. Sample rock is Tage tuff.

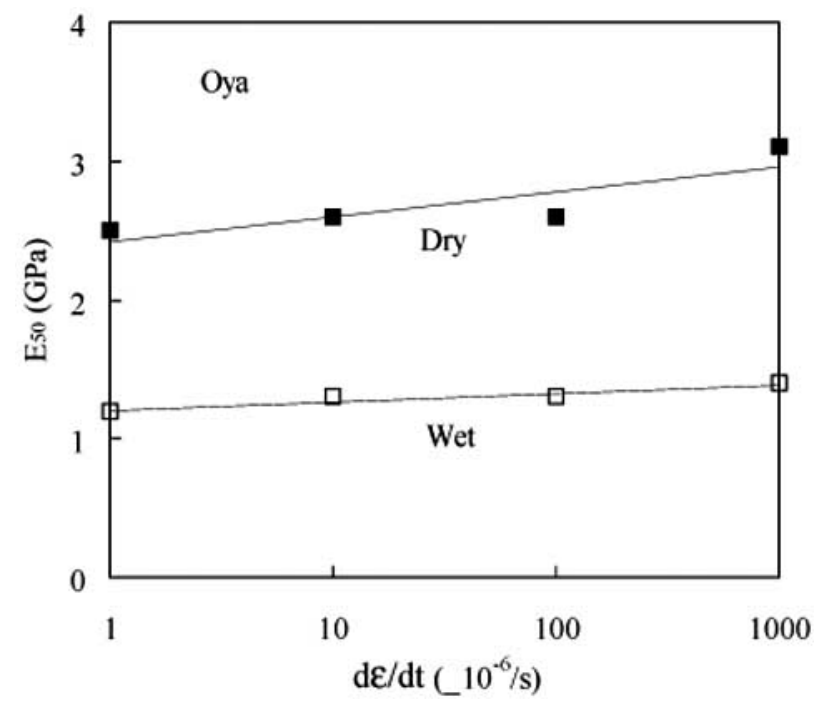

Fig. (11). Increase of Young's modulus with loading rate [5]. Sample rock is Oya tuff. 
Table 3 provides a comparison of the measured and predicted increasing rate of $E_{50}, \Delta E / E$, with a tenfold increase in strain rate. Dry Oya tuff and both dry and wet Tage tuff showed good agreement between measured and predicted increasing rates, but wet Oya tuff did not. There was a considerably greater increasing rate for wet Tage tuff compared with dry Tage tuff, while for Oya tuff, the wet rock recorded a lower increasing rate. It seems advisable to carry out additional tests of wet Oya tuff.

Let us revisit Eq. (19), which approximates the increasing rate in Young's modulus when the loading rate has been increased tenfold:

$$
\Delta E / E=\left\{1-\frac{1}{10^{1 /\left(m_{1}+1\right)}}\right\} \varepsilon_{1 s} /\left(\varepsilon_{1 s}+\lambda \sigma_{50}\right)
$$

For $m_{1}=9$, the \{\} term in Eq. (19) takes the value 0.2. If we assume that $m_{1}$ is similar across different Rock types, it is $\varepsilon_{1} /\left(\varepsilon_{1}+\lambda \sigma_{50}\right)=\varepsilon_{1} / \varepsilon$ or the fraction of irrecoverable strain that determines the extent of the dependence of Young's modulus on loading rate. The rock types examined in this study have relatively large $\varepsilon_{1} / \varepsilon$ fractions, so the loading rate-dependence was observable. In contrast, Inada granite has been reported to show no measurable loading rate-dependence [5]. There are few studies of this type, so it is necessary to examine the relationship between $\varepsilon_{1} / \varepsilon$ and loading rate-dependence of Young's modulus in future studies.

Fig. (12) provides examples of experimental results for alternating loading and un-loading during uniaxial compression tests. The samples were Kawazu tuff, and the stress level was lowered (strain was decreased) from, for example, approximately $20 \%$ of peak strength to approximately $10 \%$, then increased again to $20 \%$ to repeat the process. The slopes of the 6 solid lines in Fig. (12) indicate the $E \mathrm{e}=7.9 \mathrm{GPa}$ given in Table 1. During unloading from 8,12 or $16 \mathrm{MPa}$ in dry specimens, the slope of the unloading curve is close to Ee, but as the stress level is increased, the slope of the unloading curve increases slightly. $E \mathrm{e}$ is the slope of the unloading curve from $30 \%$ to $20 \%$ of the peak strength. During loading, cracks and pores in the rock are closed due to the increasing stress; the opposite process, re-opening of cracks and pores, does not occur to a great extent during unloading, resulting in a steeper slope for Ee during unloading than for loading.

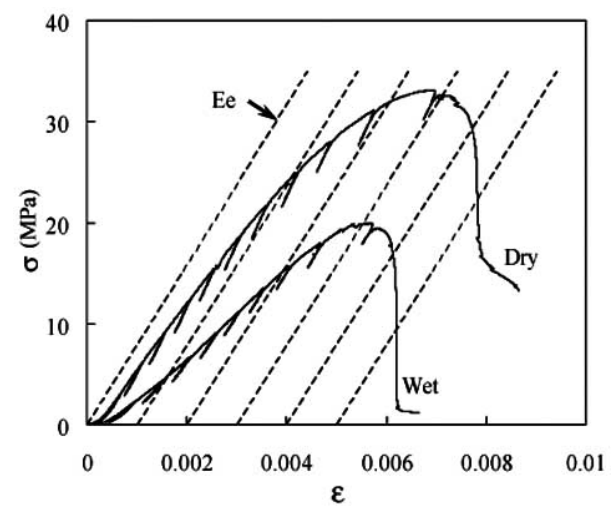

Fig. (12). Stress-strain curves of Kawazu tuff in air-dried and water saturated conditions. A specimen was unloaded and reloaded at every $10 \%$ stress levels. Modulus of straight lines is Ee.
The unloading curve from a stress of $4 \mathrm{MPa}$ is concave upward, and the slope of the curve immediately after the initiation of unloading (the tangential slope) does not differ greatly from $E$ e, although the slope gradually diminishes with progressive unloading. The displacement between the loading platens was measured with a differential transformer and the strain was calculated from this displacement; it is therefore possible that the concave-upward shape of the unloading curve from low loads was mainly due to factors at the specimen end surfaces. The slope of the unloading curve was almost exactly $E$ e in wet specimens at stresses above 7 $\mathrm{MPa}$, during both loading and unloading. Wet specimens showed the same concave-upward unloading curve shape as dry specimens when unloading from lower stresses.

The trends of unloading curves described above have also been qualitatively determined in the other rock types.

\section{CONCLUSIONS}

Many rheological models and constitutive equations have been proposed to account for the viscoelastic and timedependent behavior of rock. It has not been difficult to develop models that correctly predict single phenomena, for example, creep. Nearly all cases can be reduced to mathematical problems by approximating experimental findings with the appropriate interpolative techniques. Difficulties arise when one tries to explain several phenomena [28]. The current investigation has taken several loading conditions into account: strength tests (constant strain rate, constant stress rate), creep tests and generalized relaxation tests. We also wish to emphasize in these arguments plausible explanations for the differences in deformation recorded in wet and dry conditions.

The rheological model proposed in this report is described in Fig. (2); as noted, the spring represents elastic strain, and the dashpot irrecoverable strain. The spring expresses the strain that can be elastically recovered at any point in time; it was defined with increasing compliance (decreasing stiffness) as load is continuously applied. We used a previously published constitutive equation incorporating variable compliance as the differential equation expressing the increase in compliance. The coefficient of viscosity of the dashpot was also not a constant, but rather, showed increasing resistance to deformation according to the loading history. When strength tests were considered, dashpot deformation increased as stress gradually increased, but as the dashpot had been assigned a viscosity coefficient that increased with deformation, the deformation was never permitted to increase with strongly positive acceleration. The increase in compliance began to exert a greater influence once the stress had surpassed $80 \%$ of peak strength, although this varied with rock type; once past peak strength, especially, the dashpot did not extend, and effects of the increase in compliance became dominant.

The shape of the stress-strain curve and the loading ratedependence of the peak strength can be explained according to the proposed rheological model. We also attempted to describe other phenomena that are unexplained or inadequately explained, such as the loading rate-dependence of Young's modulus and the discrepancy between the 
observed Young's moduli of wet and dry rock. The most important result of this study is that differences in the irrecoverable strain for wet and dry rocks are the reason for differences between the Young's moduli of wet and dry rocks. Another important result is the ability of our model to predict approximate linear stress-strain curves up to high stress levels and to account for the loading rate-dependence of Young's modulus, even when considering large irrecoverable strain.

One issue remaining for future research is to improve the accuracy of the constants in the proposed model. It is especially likely that there is sizeable error in $n_{1}$. Currently, no method for accurately identifying $\mathrm{n}_{1}$ has been established. Another important issue is to identify changes inside samples corresponding to the spring and dashpot in the proposed model. Changes in compliance are probably brought about by crack development $[29,30]$. Progressive closure of pores in rock is the primary candidate for explaining dashpot deformation. This is easy to understand if only compression tests are considered, but Shimizu et al. [31] reported qualitatively similar irrecoverable strain in uniaxial tension tests. We believe that future investigations must take account of irrecoverable strain under tensile stresses as well as under compressive stresses.

\section{ACKNOWLEDGEMENT}

This research was partially supported by the Ministry of Education, Science, Sports and Culture, Grant-in-Aid for Scientific Research (B) 17360430.

\section{APPENDIX A: LINEARITY OF THE STRESS-STRAIN CURVE AT LOW STRESS LEVELS}

Fig. (A1) shows an approximation of the stress-strain curve using $\sigma^{*}=\varepsilon^{* b}$; if $b$ is in the range $0.8-1.2$, the stressstrain curve appears linear. Linearity is most complete when $\sigma^{*}$ is greater than 0.2 .

Equation (6) was used to calculate the stress-strain curve at a stress equal to $50 \%$ of peak strength, varying $\varepsilon_{1} / \varepsilon_{3}$ and $\left(n_{1}+1\right) /\left(m_{1}+1\right)$. The calculated stress-strain curve was fitted to the $\sigma^{*}=\varepsilon^{* b}$ curve by searching for the best value of $\boldsymbol{b}$. The results are shown in Fig. (A2). $\boldsymbol{b}$ can be anywhere in the range of $0.8-1.2$, except for the stresses in the upper left or right. The $\triangle$ in the figure indicate the positions of 4 rock types.

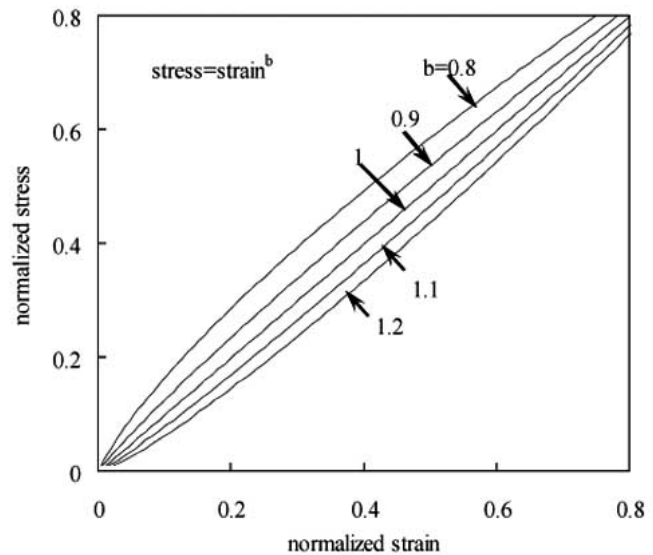

Fig. (A1). Normalized stress-strain curves approximated by the equation $\sigma^{*}=\varepsilon^{* b}$.

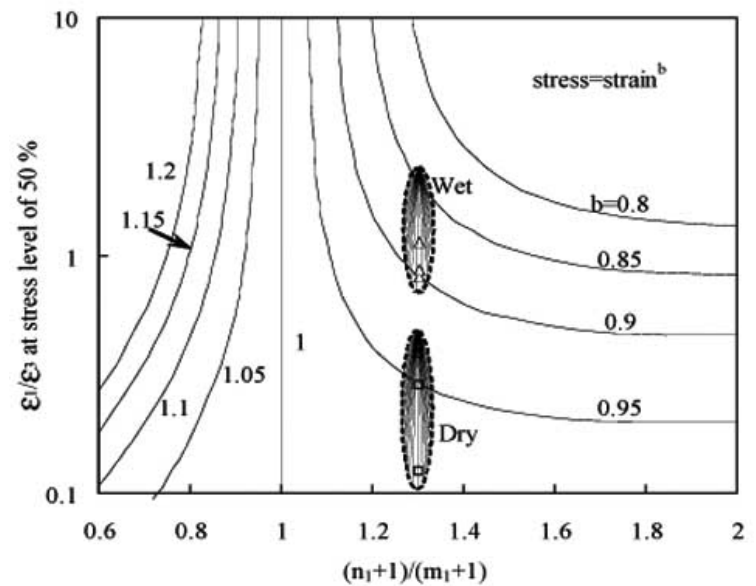

Fig. (A2). Value of $b$ determined to fit for stress-strain curve calculated by the Eq. (6). Symbols, $\triangle$, denote locations of four sample rocks in air-dried and water-saturated conditions.

\section{REFERENCES}

[1] E. Z. Lajtai, R. H. Schmidtke, and L. P. Bielus, "The effect of water on the time-dependent deformation and fracture of a granite", Int. J. Rock Mech. Min. Sci. Geomech. Abstr., Vol. 24, pp. 247-255, 1987.

[2] N. Cristescu, "Elastic/viscoplastic constitutive equations for rock", Int. J. Rock Mech. Min. Sci. Geomech. Abstr., Vol. 24, pp. 271-282, 1987.

[3] J. Kodama, T, Goto, Y. Fujii, Y. Yoshida, and K. Itakura, "Creep deformation and creep life of Noboribetsu welded tuff under airdried and water-saturated conditions", J. Min. Metall. Inst. Japan, Vol. 117, pp. 718-724, 2001. (in Japanese)

[4] S. Okubo, and K. Fukui, "Long-term creep test and constitutive equation of Tage tuff. J. Min. Metall. Inst. Japan, Vol. 118, pp. 3641, 2002. (in Japanese)

[5] S. Okubo, K. Fukui, and J. Xu, "Loading rate dependency of Young's modulus of rock", J. Min. Metall. Inst. Japan, Vol. 117, pp. 29-35, 2001. (in Japanese)

[6] S. Okubo, K. Fukui, K. Hashiba, and K. Shin, "A consideration on probability distribution of strength and creep life of rocks", J. Min. Metall. Inst. Japan, Vol. 119, pp. 734-740, 2003. (in Japanese)

[7] H. S. Jeong, Y. Obara, and K. Sugawara, "Strength of Kumamoto andesite in non-atmospheric environments", J. Min. Metall. Inst. Japan, Vol. 119, pp. 9-16, 2003. (in Japanese)

[8] Y. Nara, Y. Ohno, Y. Imai, K. Kaneko, "Anisotropy and grain-size dependency of crack growth due to stress corrosion in granite", $J$. Min. Metall. Inst. Japan, Vol. 120, pp. 25-31, 2004. (in Japanese)

[9] S. Okubo, and Y. Nishimatsu, "Uniaxial compression testing using a linear combination of stress and strain as the control variable", Int. J. Rock Mech. Min. Sci. Geomech. Abstr., Vol. 22, pp. 323-330, 1985.

[10] K. Shin, S. Okubo, K. Fukui, and K. Hashiba, "Variation in strength and creep life of six Japanese rocks", Int. J. Rock Mech. Min. Sci., Vol. 42, pp. 251-260, 2005.

[11] X. J. Gao, S. Okubo, K. Fukui, and K. Kaneda, "An investigation on landslides and rock characteristic around the Three Gorges reservoir", J. Min. Metall. Inst. Japan, Vol. 122, pp.26-34, 2006. (in Japanese)

[12] S. Y. Chu, "Time-dependency of rocks in water-saturated condition", Doctoral thesis of the University of Tokyo, pp. 97-100, 1995. (in Japanese)

[13] JNC-Japan Nuclear Cycle Development Inst., "Project to establish the scientific and technical basis for HLW disposal in Japan (Supporting report2)", JNC TN1400 99-022, Tokai-mura, Ibaraki, A-12, 1999. (in Japanese)

[14] V. Palchik, and Y. H. Hatzor, "The influence of porosity on tensile and compressive strength of porous chalks", Rock Mech. Rock Engng., Vol. 37, pp. 331-341, 2004. 
[15] S. Okubo, and Y. Nishimatsu, "Evaluation of rock strength by longitudinal-wave-velocity measurement from the stochastic point of view", J. Min. Metall. Inst. Japan, Vol. 96, pp. 449-453, 1980. (in Japanese)

[16] O. Anderson, and P. Grew, "Stress corrosion theory of crack propagation with application to geophysics", Reviews Geophysics and Space Physics, Vol. 15, pp. 77-104, 1977.

[17] H. S. Jeong, and Y. Obara, "Strength of Kumamoto andesite in non-atmospheric environments", J. Min. Metall. Inst. Japan, Vol. 118, pp. 599-604, 2002. (in Japanese)

[18] S. Okubo, and Y. Nishimatsu, "Creep behaviour and constitutive equation of Sanjome andesite and Kawazu tuff", J. Min. Metall. Inst. Japan, Vol. 102, pp. 395-400, 1986. (in Japanese)

[19] S. Okubo, Y. Nishimatsu and, K. Fukui, "Complete creep curves under uniaxial compression”, Int. J. Rock Mech. Min. Sci. Geomech. Abstr., Vol. 28, pp. 77-82, 1991.

[20] S. Okubo, "Analytical consideration of constitutive equation of variable compliance type. J. Min. Metall. Inst. Japan, Vol. 108, pp. 601-606, 1992. (in Japanese)

[21] S. Okubo, and K. Fukui, "An Analytical Investigation of a Variable-Compliance-type Constitutive Equation", Rock Mech. Rock Engng., Vol. 39, pp. 233-253, 2006.

[22] S. Okubo, "Creep of rocks", J. Min. Metall. Inst. Japan, Vol. 107, pp. 245-252, 1991. (in Japanese)

[23] K. Fukui, S. Okubo, and Y. Nishimatsu, "Generalized relaxation behaviour of rock under uniaxial compression", J. Min. Metall. Inst. Japan, Vol. 108, pp.543-548, 1992. (in Japanese)
[24] K. Hashiba, S. Okubo, and K. Fukui, "Loading rate dependency of peak and residual strengths of rocks", J. Min. Metall. Inst. Japan, Vol. 121, pp. 11-18, 2005. (in Japanese)

[25] S. Okubo, and Y. Nishimatsu, "The uniaxial compressive test of rocks controlled by a negative feed back of stress rate", J. Min. Metall. Inst. Japan, Vol. 100, pp. 1052-1056, 1984. (in Japanese)

[26] S. Okubo, Y. Nishimatsu, M. Akiyama, and T. Tatsumi, "Study on impact penetration test of rock", J. Min. Metall. Inst. Japan, Vol. 108, pp. 134-140, 1992. (in Japanese)

[27] JNC-Japan Nuclear Cycle Development Inst., "Fundamental study on long-term stability of rock from the macroscopic point of view", JNC TJ7499 2004-002, Tokai-mura, Ibaraki, Chapter 2, 2004. (in Japanese)

[28] P. K. Kaiser, and N. R. Morgenstern, "Phenomenological model for rock with time-dependent strength", Int. J. Rock Mech. Min. Sci. Geomech. Abstr., Vol. 18, pp. 153-165, 1981.

[29] R. L. Kranz, "Crack growth and development during creep of Barre granite", Int. J. Rock Mech. Min. Sci. Geomech. Abstr., Vol. 16, pp. 23-35, 1979.

[30] R. L. Kranz, "Crack-crack and crack-pore interactions in stressed granite", Int. J. Rock Mech. Min. Sci. Geomech. Abstr., Vol. 16, pp. 37-47, 1979.

[31] T. Shimizu,, K. Fukui, S. Okubo, M. Akiyama, "Change of unloading compliance under uniaxial tensile stress of rock", Proc. J. Min. Metall. Inst. Japan annual spring meeting, pp. 262-263, 1997. (in Japanese)

(c) Okubo et al.; Licensee Bentham Open.

This is an open access article distributed under the terms of the Creative Commons Attribution License (http://creativecommons.org/licenses/by/2.5/), which permits unrestrictive use, distribution, and reproduction in any medium, provided the original work is properly cited. 